\title{
Transferring Protection: Adenosine as the Lone Ranger?
}

\author{
Editorial to: "Remote Cardioprotection by Transfer of Coronary Effluent from Ischemic \\ Preconditioned Rabbit Heart Preserves Mitochondrial Integrity and Function \\ via Adenosine Receptor Activation" by C.H. Leung et al.
}

\author{
Qun Chen • Edward J. Lesnefsky
}

Published online: 15 October 2013

(C) Springer Science+Business Media New York 2013

Coronary effluent from a heart undergoing brief periods of ischemia and reperfusion that leads to the cytoprotection of ischemic preconditioning decreases injury when administered before ischemia to a second heart; the "transfer of cardioprotection" phenomena [1]. In the current issue of Cardiovascular Drugs and Therapy, Dr. Leung and colleagues replicate the "transfer of cardioprotection" in an isolated rabbit heart model [2]. The authors hypothesize that increased adenosine content in coronary effluent from the first ischemic preconditioned heart is the key mediator of the protection transferred to the second heart. Four lines of evidence support their hypothesis: (1) the content of adenosine in collected coronary effluent from preconditioned hearts is dramatically increased; (2) the phenomena of "transfer protection" is blocked by a non-selective adenosine receptor inhibitor; (3) direct addition of adenosine into coronary effluent from nonpreconditioned hearts provides a similar reduction in infarct size compared to coronary effluent from the preconditioned hearts; (4) mitochondrial function is improved in hearts treated by coronary effluent from preconditioned hearts. They conclude that the "transfer of protection" is mediated

Q. Chen · E. J. Lesnefsky

Department of Medicine (Division of Cardiology, Pauley Heart Center), Virginia Commonwealth University, Richmond, VA 23298, USA

\section{E. J. Lesnefsky}

Department of Biochemistry, Virginia Commonwealth University, Richmond, VA 23298, USA

\section{E. J. Lesnefsky}

McGuire Department of Veterans Affairs Medical Center, Richmond, VA 23249, USA

\section{E. J. Lesnefsky $(\bowtie)$}

Cardiology Section, Medical Service 111(J), McGuire VA Medical Center, 1201 Broad Rock Boulevard, Richmond, VA 23249, USA

e-mail: ejlesnefsky@vcu.edu by an increased adenosine content in coronary effluent through preservation of mitochondrial integrity.

Activation of adenosine receptors provides solid cardioprotection in experimental hearts following ischemiareperfusion [2-4]. Adenosine treatment also tended to improve outcome in a meta-analysis of clinical trials [5], though outcomes did not reach statistical significance [5], mirroring the failure to demonstrate benefit in the largest single trial [6]. Ischemic damage to mitochondria is a key mechanism of cardiac injury during reperfusion [7]. Protection of mitochondria during ischemia decreases cardiac injury during the subsequent reperfusion [8]. In Dr. Leung's study, perfusion of collected coronary effluent from preconditioned hearts before ischemia improved the mitochondrial function in the recipient heart, supporting the notion that "transfer cardioprotection" is mediated by mitigating mitochondrial damage during ischemia-reperfusion.

Although addition of adenosine into control coronary effluent reduces the infarct size to a similar extent as treatment by coronary effluent from preconditioned hearts, there are different effects on mitochondrial function between these two treatments. Ischemic preconditioning protects mitochondria through inhibition of mitochondrial permeability transition pore (MPTP) [9]. The MPTP is also inhibited in hearts treated by ischemic postconditioning [10,11]. In the current study, mitochondrial respiration and the integrity of outer mitochondrial membrane are significantly improved in coronary effluent treated hearts. However, pure adenosine treatment improved outer membrane integrity but did not protect the electron transport chain. The adenosine treatment results in a better coupled mitochondrial respiration through an unclear mechanism. These results suggest that adenosine is not the sole substance that induces the transferred protection. Other molecular entities, especially small peptides, may contribute to this protection [12]. The preliminary proteomic study is an exciting step to further clarify the molecular targets in this 
transfer cardioprotection model [2]. Furthermore, interaction with opioid receptors [13] and other signaling systems, including STAT3 $[14,15]$ are contributors.

Remote conditioning is a cardio protective strategy achieved by applying cycles of ischemia-reperfusion to a non-cardiac tissue. Although the remote conditioning has major clinical relevance and is currently in clinical trials [16-19], the mechanism by which the distant stimuli confer cardioprotection remains unclear. Experimental evidence indicates that adenosine, opioids, bradykinin and small hydrophobic molecules are involved in the remote conditioningmediated protection [20-22]. Remote conditioning appears to reduce Bax protein expression and increase $\mathrm{Bcl}-2$ protein expression thereby reducing the likelihood of mitochondrial outer membrane permeability (MOMP) and activation of programmed cell death [23]. Whether the transfer of coronary effluent will impact the ratio of bcl-2/bax, depleted during ischemia by a mitochondria-dependent mechanism [24], needs to be clarified. Supplementation of adenosine into cardioplegia reduces ischemia-reperfusion injury [25]. Addition of collected coronary effluent form preconditioned hearts may further enhance the cardioprotective effect of cardioplegia. There has been substantial discussion regarding the therapeutic challenge of translating cardioprotective interventions from the basic science laboratory to the clinical realm [26], including the selective activation of adenosine receptors [5]. Perhaps the therapeutic potential of remote conditioning is related to adenosine driven mechanisms [4] acting in concert with other protective mediators that via signalinginduced [26, 27], or perhaps direct therapeutic targeting [28], modulate the mitochondria and the jeopardized myocyte to elicit cardioprotection. Perhaps the "transfer of cardioprotection" approach utilized in the study of Leung and colleagues [2], implied by the disparate mitochondrial responses to the single agent vs. the multi-compound treatment, suggests that complimentary interventions are needed to achieve cardioprotective success in the more complex clinical realm. When The Lone Ranger adenosine rides to the rescue, perhaps the complimentary support of other mediators as Tonto should not be forgotten.

This work was supported by a Scientist Development Grant (11SDG5120011) from the American Heart Association (QC) and the Office of Research and Development, Medical Research Service, Department of Veterans Affairs (EJL, QC), and the Pauley Heart Center, Virginia Commonwealth University.

\section{References}

1. Dickson EW, Lorbar M, Porcaro WA, et al. Rabbit heart can be "preconditioned" via transfer of coronary effluent. Am J Physiol. 1999;277(6 Pt 2):H2451.

2. Leung CH, Wang L, Nielsen JM, et al. Remote cardioprotection by transfer of coronary effluent from ischemic preconditioned rabbit heart preserves mitochondrial integrity and function via adenosine receptor activation. Cardiovasc Drugs Ther. 2014;28: this issue

3. Cohen MV, Downey JM. Adenosine: trigger and mediator of cardioprotection. Basic Res Cardiol. 2008;103(3):203.

4. Yang X, Cohen MV, Downey JM. Mechanism of cardioprotection by early ischemic preconditioning. Cardiovasc Drugs Ther. 2010; 24(3):225.

5. Singh M, Shah T, Khosla K, Singh P, Molnar J, Khosla S, et al. Safety and efficacy of intracoronary adenosine administration in patients with acute myocardial infarction undergoing primary percutaneous coronary intervention: a meta-analysis of randomized controlled trials. Ther Adv Cardiovasc Dis. 2012;6(3):101.

6. Ross AM, Gibbons RJ, Stone GW, Kloner RA, Alexander RW. A randomized, double-blinded, placebo-controlled multicenter trial of adenosine as an adjunct to reperfusion in the treatment of acute myocardial infarction (AMISTAD-II). J Am Coll Cardiol. 2005;45(11):1775.

7. Murphy E, Steenbergen C. Mechanisms underlying acute protection from cardiac ischemia-reperfusion injury. Physiol Rev. 2008;88(2):581.

8. Chen Q, Moghaddas S, Hoppel CL, Lesnefsky EJ. Reversible blockade of electron transport during ischemia protects mitochondria and decreases myocardial injury following reperfusion. J Pharmacol Exp Ther. 2006;319(3):1405.

9. Weiss JN, Korge P, Honda HM, Ping P. Role of the mitochondrial permeability transition in myocardial disease. Circ Res. 2003;93(4):292.

10. Chen Q, Paillard M, Gomez L, Li G, Hu Y, Lesnefsky EJ. Postconditioning modulates ischemia-damaged mitochondria during reperfusion. J Cardiovasc Pharmacol. 2012;59(1):101.

11. Paillard M, Gomez K, Augeul L, Loufouat J, Lesnefsky EJ, Ovize M. Postconditioning inhibits mPTP opening independent of oxidative phosphorylation and membrane potential. J Mol Cell Cardiol. 2009;46:902-9.

12. Przyklenk K. 'Going out on a limb': SDF-1alpha/CXCR4 signaling as a mechanism of remote ischemic preconditioning? Basic Res Cardiol. 2013;108(5):382.

13. Tubbs RJ, Porcaro WA, Lee WJ, et al. Delta opiates increase ischemic tolerance in isolated rabbit jejunum. Acad Emerg Med. 2002;9(6):555.

14. Heusch G. Cardioprotection: chances and challenges of its translation to the clinic. Lancet. 2013;381(9861):166.

15. Szczepanek K, Chen Q, Derecka M, et al. Mitochondrial-targeted signal transducer and activator of transcription 3 (STAT3) protects against ischemia-induced changes in the electron transport chain and the generation of reactive oxygen species. J Biol Chem. 2011;286(34):29610.

16. Przyklenk K, Bauer B, Ovize M, Kloner RA, Whittaker P. Regional ischemic 'preconditioning' protects remote virgin myocardium from subsequent sustained coronary occlusion. Circulation. 1993;87(3): 893.

17. Takagi H, Manabe H, Kawai N, Goto SN, Umemoto T. Review and meta-analysis of randomized controlled clinical trials of remote ischemic preconditioning in cardiovascular surgery. Am J Cardiol. 2008;102(11):1487.

18. Candilio L, Hausenloy DJ, Yellon DM. Remote ischemic conditioning: a clinical trial's update. J Cardiovasc Pharmacol Ther. 2011;16(3-4):304.

19. Ovize M, Thibault H, Przyklenk K. Myocardial conditioning: opportunities for clinical translation. Circ Res. 2013;113(4):439.

20. Tapuria N, Kumar Y, Habib MM, Abu Amara M, Seifalian AM, Davidson BR. Remote ischemic preconditioning: a novel protective method from ischemia reperfusion injury - a review. J Surg Res. 2008;150(2):304.

21. Vinten-Johansen J, Shi W. The science and clinical translation of remote postconditioning. J Cardiovasc Med (Hagerstown). 2013;14(3):206. 
22. Przyklenk K, Whittaker P. Genesis of remote conditioning: action at a distance- 'hypotheses non fingo'? J Cardiovasc Med (Hagerstown). 2013; 14(3):180.

23. Tang YH, Xu JJ, Li JX, Cheng XS. Remote postconditioning induced by brief pulmonary ischemia and reperfusion attenuates myocardial reperfusion injury in rabbits. Chin Med J (Engl). 2011;124(11):1683.

24. Chen Q, Lesnefsky EJ. Blockade of electron transport during ischemia preserves bcl-2 and inhibits opening of the mitochondrial permeability transition pore. FEBS Lett. 2011;585(6):921.

25. Djabir Y, Letson HL, Dobson GP. Adenosine, lidocaine, and Mg2+ (ALM) increases survival and corrects coagulopathy after eightminute asphyxial cardiac arrest in the rat. Shock. 2013;40(3):222.
26. Gomez L, Paillard M, Price M, et al. A novel role for mitochondrial sphingosine-1-phosphate produced by sphingosine kinase-2 in PTPmediated cell survival during cardioprotection. Basic Res Cardiol. 2011;106(6):1341.

27. Heusch G, Musiolik J, Gedik N, Skyschally A. Mitochondrial STAT3 activation and cardioprotection by ischemic postconditioning in pigs with regional myocardial ischemia/reperfusion. Circ Res. 2011; 109(11): 1302

28. Chen Q, Ross T, Hu Y, Lesnefsky EJ. Blockade of electron transport at the onset of reperfusion decreases cardiac injury in aged hearts by protecting the inner mitochondrial membrane. J Aging Res. 2012; 2012:753949. 